\title{
LA PRIMERA BOTICA DE LOS HOSPITALES DE LA CIUDAD DE LIMA EN EL SIGLO XVI
}

\author{
Miguel Rabí Chara \\ Profesor Universitario, Ministerio de Salud de Perú.
}

\section{RESUMEN}

El autor hace una reseña detallada sobre los primeros hospitales establecidos en la Ciudad de los Reyes de Lima, a partir de 1549; y en especial un comentario sobre la primera botica recibida en 1551 para dichos hospitales, junto con el contrato de compañía para su funcionamiento.

\section{SUMMARY}

The first hospitals established in south America, specifically in Lima in 1549, are reviewed by the author, hightlighting the first pharmacy arrived in 1551 for those hospitals, including the complete inventary and values of it's contents. In the same way the contract for its management is described and analyzed.

\section{ANTECEDENTES}

La primera enfermería y a la vez casa-albergue y hospital se estableció en 1538, a los tres años de fundada la Ciudad de los Reyes de Lima, como aparece en los Libros de Cabildos de nuestra metrópoli, teniendo en cuenta la especial preocupación e interés del fundador, don Francisco Pizarro, de dar cumplimiento a las Capitulaciones de 1529 , por lo que en el primer reparto de solares efectuado a continuación del acto fundacional del día 18 de enero de 1535, se asignaron dos solares contiguos a los señalados para la Religión de Santo Domingo, destinados para el hospital de la Ciudad, como reseñan las crónicas, en la calle que hasta hoy conserva su clásica denominación: «Rinconada de Santo Domingo».

Concluídas las guerras civiles entre los conquistadores y pacificado el Reino del Perú, entre los años 1545 y 1548 comienzan a edificarse los nuevos Hospitales de la Ciudad, en lugar más adecuado, amplio y ventilado, por virtud de la especial preocupación del Arzobispo de los Reyes, Fray Jerónimo de Loaisa, en favor de los naturales, y del Cabildo de los Reyes, por los demás pobladores de la naciente capital del Virreinato del Perú. 
Es así que en Enero de 1549 abre sus puertas el recién construído Hospital de Santa Ana de los Naturales, financiado en forma exclusiva con los aportes y donaciones que en forma especial hizo el Arzobispo Loaisa, en su doble función pastoral y social habida cuenta de la especial designación que ostentaba de Protector General de los Naturales, otorgada por el Emperador Carlos I.

Entretanto, el Hospital de la Ciudad, iniciado en 1545 sobre los terrenos adquiridos al espadero Juan de Morales, recién logra entrar en funcionamiento a partir de 1551 y desde entonces, consolidado con la antigua Enfermería de la Calle de la Rinconada, con la presencia del Presbítero don Francisco de Molina, con el apoyo del Cabildo de la Ciudad, donaciones y aportes de colaboradores, toma la denominación de «San Andrés».

En esta primera etapa de desarrollo de los Hospitales, el Cabildo y el Arzobispo acuerdan unir sus esfuerzos para tener una sola administración, reduciendo los gastos y aplicando los recursos disponibles a la atención de los numerosos enfermos, alimentación, vestuario, personal profesional (médicos, cirujanos, boticarios, auxiliares, etc. ) La administración conjunta de los dos Hospitales se cumplió entre los años 1551 y 1555, resolviendo ambos Patronos, el Arzobispo y el Cabildo, concluirla previa rendición de cuentas y liquidación de gastos por el Mayordomo Administrador designado por las dos partes.

\section{COMPRA DE LA BOTICA}

Es precisamente en el año 1551, a que se refiere este análisis, cuando se realiza la adquisición de la Botica completa proveniente de Sevilla, por decisión del Arzobispo de Los Reyes, Fray Jerónimo de Loaisa, con la que se inicia la preparación de las recetas en el Hospital de Santa Ana de los Naturales, cesando así la intervención de boticarios y organizándose adecuadamente la atención de los numerosos pacientes, con la constitución de las Hermandades o Hermanos 24 y las Ordenanzas que para este efecto dictó el propio Arzobispo. Bien conocía el ilustre y benéfico Prelado que era necesario contar con la confianza del aborigen, tanto para que manifestara sus necesidades, reclamaciones y aspiraciones, como para poder transmitirle los conocimientos espirituales y materiales tendentes a lograr su transformación y doctrinamiento; por consiguiente debemos considerar las especiales dificultades de comunicación, de entendimiento y de relación entre los dos grandes grupos de pobladores, con conocimientos y mentalidades distintas, que desde entonces debieron coexistir en la nueva Ciudad sede principal del Virreinato y en la formación de la estructura social propia del momento histórico.

A este acercamiento humano y cristiano, vino a contribuir en forma eficaz la acción personal del Arzobispo Loaisa, no sólo de lograr el doctrinamiento de los pobla- 
dores, sino en forma especial velar por su salud corporal, poniendo a su alcance un eficaz servicio de salud, paralelo al que desarrollaba el Cabildo, que luego se denominaría Real Hospital de San Andrés.

La separación administrativa de los dos Hospitales (de naturales y de españoles) puede fundamentarse en las siguientes razones: a) los dos servicios no se encontraban en el mismo nivel de desarrollo, edificación y calidad de atención; b) el dedicado a los naturales se encontraba en mejor pie que el de españoles, tanto en su fábrica como en la organización de sus servicios; c) la obtención de ingresos por el Hospital de los naturales, además de limosnas, donaciones reales, censos, legados y otros, registraba un considerable volumen, creciente cada año; d) la plena dedicación personal del Arzobispo Loaisa, que brindaba a esta obra de protección y cuidado de los naturales, no tenía paralelo con la que realizaba el Cabildo, mayormente preocupado por el desarrollo de la Ciudad y de sus moradores, por las nuevas construcciones y por la obtención de rentas para su mejor gobierno.

Es en esta forma como el Arzobispo decide considerar inadecuada la unión de los dos Hospitales, inclinándose por la administración independiente de cada uno, a lo que debemos agregar en forma especial, la adquisición de la Botica completa para su querido Hospital, desde entonces denominado de «Santa Ana de los Naturales». Esta compra permitía atender mejor el cada vez mayor número de enfermos, las epidemias y plagas, lograr el despacho inmediato de las recetas y no depender en grado alguno de boticas y boticarios de la Ciudad.

\section{CÓMO SE COMPRÓ LA BOTICA.}

La referencia concreta de la compra de la Botica, la podemos señalar realizada el día 3 de Abril de 1551, con la intervención del Mayordomo Diego Díaz de Becerril, el Boticario del Hospital, Francisco de Bilbao y el mercader Pedro de la Palma, con larga memoria de inventario y valorización de productos, insumos, semillas y frutos, fijándose el precio total de la venta en 3.400 pesos de oro.

Se consigna en los instrumentos contractuales, con toda formalidad, que la Botica había llegado al Puerto de El Callao de la Ciudad de los Reyes, en la nave «Santa María La Bella» a cargo del Maestre Julio Díaz Machín, contenida en treinta cajones de madera clavados y sellados. Y al haber aprobado el Arzobispo la compra, se procede seguidamente a realizar el inventario y memoria del contenido de cada uno de los treinta cajones, detallándose uno a uno los contenidos (medicamentos, insumos básicos, plantas secas, semillas, aguas, jarabes, elixires, soluciones, polvos, utensilios, libros, mobiliario, equipos, etc.) con sus respectivos precios. 


\section{PERSONAS QUE INTERVIENEN}

Son numerosas las personas que participan en esta operación contractual, atendiendo su importancia y especial naturaleza social, como se observa seguidamente:

a) El Arzobispo de los Reyes, Fray Jerónimo de Loaisa, en su calidad de Patrono de los dos Hospitales, al haber otorgado facultades al nuevo Mayordomo Gonzalo López, para concertar esta operación, mediante escrituras de poder de fechas 4 y 16 de Febrero de 1552.

b) El Cabildo de la Ciudad representado por Juan de Astudillo Montenegro, Regidor Mayor, y Jerónimo de Silva, Mayordomo de la Ciudad, en su calidad de Diputados designados para este fin.

c) El Boticario Francisco de Bilbao, a cargo del respectivo establecimiento, y que provenía del Reino de Chile.

d) Gonzalo López, como nuevo Mayordomo designado por los Patronos de los dos Hospitales, con los respectivos poderes para intervenir en este acto.

f) Pedro de la Palma, mercader y titular de la Botica que había embarcado en la Ciudad de Sevilla y que había trasladado vía Panamá, hasta la Ciudad de los Reyes, en su calidad de vendedor.

g) Diego Díaz Becerril, Mayordomo de los Hospitales hasta el año de 1551, quien suscribió el instrumento de compra de la Botica con Pedro de la Palma, y que el día 20 de Octubre de 1551hace entrega formal al Boticario Francisco de Bilbao.

\section{NATURALEZA DEL CONTRATO}

Los actos contractuales que se celebran son cuatro, que se realizan sucesivamente, constituyendo el cuerpo central de la operación:

a) Ratificación de los poderes otorgados por los Patronos al Mayordomo de los Hospitales Gonzalo López.

b) Confirmación de la designación de Francisco de Bilbao como Boticario de los dos Hospitales.

c) Operación formal de compra de la Botica a Pedro de la Palma, de acuerdo con la memoria, inventario y valorización efectuada y

d) Contrato de compañía para el funcionamiento de la Botica por el plazo de seis años, que celebran el Boticario Francisco de Bilbao y el Mayordomo Gonzalo López.

Con relación al inciso c) precedente, debemos decir que el precio total de 3.400 pesos de oro pactado por la Botica, se pagó en dos partes, una primera de 1.700 pesos 
a los treinta días siguientes de la entrega física de la Botica, y la segunda a los ocho meses calendario siguientes al día de la entrega; con descuento de las cosas faltantes, que estuviesen quebradas, rotas o no utilizables, como ampliamente relaciona la memoria de 3 de Abril de 1551, a que se ha hecho referencia.

\section{ENTREGA DE LA BOTICA}

El día 3 de Enero de 1552 se realiza la entrega y recepción de la Botica, luego de haberse terminado la revisión detallada de cada una de las treinta cajas y haberse extendido la memoria consiguiente; certificación que suscribe el Boticario Francisco de Bilbao ante el Escribano Real Diego Gutiérrez. En cuyo caso, el término de los treinta días para efectuar el pago de la mitad del precio convenido, venció el día 2 de Febrero de 1552, y de esta fecha en adelante se calcularon los ocho meses para el pago del saldo del precio.

\section{CONTRATO DE COMPAÑÍA}

Merece considerar esta parte del instrumento, a la vez que para mencionar la solemnidad acordada por las partes para el más adecuado funcionamiento de la primera Botica de los Hospitales de la Ciudad, y la grave responsabilidad que asumían los interesados, en este caso Boticario y Mayordomo, Francisco de Bilbao y Gonzalo López, quienes acuerdan señalar como fecha de inicio de la compañía el día 20 de Octubre de 1551, esto es unos meses antes; como una forma de ratificación de actos precedentes, pues debemos considerar que la escritura se extiende ante el Escribano Diego Gutiérrez el día 9 de Marzo de 1552.

Las reglas de funcionamiento de la compañía consignadas por los socios, son las siguientes:

1.- Se fija en seis años el plazo de duración del contrato de explotación de la Botica, contados a partir del día 20 de Octubre de 1551.

2.- Prohibición absoluta de vender la Botica a terceros, con el fin de garantizar su dedicación exclusiva para los pacientes de los Hospitales de Naturales y de Españoles.

3.- Manejo y beneficio de las medicinas con arreglo al uso y costumbre de los boticarios, atendiendo y despachando las medicinas prescritas por los médicos y cirujanos de los Hospitales, como por los de la Ciudad.

4.- Obligación por parte de Francisco de Bilbao de reemplazar los medicamentos que faltaren y suministrar los que se necesitaren. 
5.- Conducción de la Botica por Francisco de Bilbao con todo celo, eficiencia y diligencia, como todo buen Boticario actúa habitualmente.

6.- Compromiso de suministrar medicamentos buenos y frescos, recetados a los enfermos de los Hospitales, sin cargo ni pago alguno.

7.- Revisión periódica de la Botica por el Médico de los Hospitales, para tasar y verificar la buena calidad de las medicinas existentes, con obligación del Boticario de reemplazar a su costa las declaradas inadecuadas o no aptas para las personas.

8.- A modo de ingreso, el Hospital percibiría del Boticario, cuatrocientos pesos de oro cada año, pagaderos por tercios, durante toda la vigencia del contrato.

9.- Obligación del Boticario de suministrar medicinas iguales a las recibidas en la memoria inicial, y asimismo, devolverlas completas al fenecer la compañía, junto con el «arnés» de la Botica, herramientas, utensilios, implementos, etc., con obligación de reponer lo faltante, y en su defecto pagar su justo valor.

10.- Autorización al Boticario para vender medicinas «para la calle», esto es atender los pedidos del público, lo que le permitía así obtener ingresos sin dar cuenta o participación alguna al Hospital.

\section{COMENTARIO SOBRE LA BOTICA}

En este valioso documento que analizamos, existe información detallada sobre los precios de las medicinas, teniendo en consideración su largo desplazamiento desde el Puerto de Sevilla hasta el de El Callao, además de otras importantes referencias que reseñamos a continuación:

- Los derechos de Aduana de Indias ascendieron a $4.500 \mathrm{~ms}$.

- El derecho de Averías fue de $5.820 \mathrm{~ms}$.

- El seguro total de la Botica ascendió a 750 ducados, esto es el seis por ciento sobre el valor total de $16.865 \mathrm{~ms}$.

- El arreglo o acondicionamiento de la Botica por el Carpintero Alonso Gómez, importó la suma de $6.000 \mathrm{~ms}$.

- Las treinta cajas de madera en que venía estibada la Botica, tenían de largo cada una seis palmos como mínimo.

- Los anaqueles o estantes estaban formados por barretas de madera doradas.

- Encontramos: frascos azules, redomas valencianas, almireces grandes y pequeños, cedazos blancos y prietos, un espatulero en oro fino para evitar impurezas, peroles de cobre con doble baño de estaño, redomas tapas con papel pergamino y cera; alambiques o alquitaras con las surtenejas; espumaderas, cazos grandes y pequeños; cajas para píldoras; jarronas preparadas en vaseras, 
espuertas a base de esparto y palma;frascos con culebras y serpientes en alcohol; una bacía de metal para calcular las medidas; embudos de latón de hoja de Milán; una balanza con pesas de plata y cordoncillos de seda; perolitos de plata y de hierro esmaltado; vasijas de vidrio, etc.

- Entre las medicinas, podemos destacar: píldoras de lipodio, trociscos de Mur o sea mirra; mirabolanos, cálamo aromático, nuez moscada, euforbio, alquitira blanca, cardamomo, nenúfares blancos, oropimente, orozús, oruga, violetas, azufeifas, cenrrubio, tamarog indio, polipodio seco y morado, pimienta larga, vitriolo, lupinos, sal gema, ben blanca, adormideras, bayas de laurel, alumbre, azúcar cande y rosada, almáciga, esclarimente, pasas, simiente de ortigas, ungüentos diversos (confortativo, de Agrippa, populeon, sopilativo, apostolorum, cetrino, marciatón de Altea, etc.), aceites (vilado, de manzanilla,de adormideras,de ungüento Agrippa, de mata de Euforbio, de ajonjolí, de eneldo,de Elbio, de alacranes, de estoraque, de trementinas, de almendras, de mostaza, de azahar, de espiquenardi, membrillo, almáciga, colarménico, abrótano, ruibarbo, etc.)

- Como puede verse de la anterior reseña, era la Medicina de España que llegaba a América, al Nuevo Mundo, llevando todo el conocimiento del mundo cristiano, en síntesis maravillosa de Grecia, Roma, Arabes y las célebres Escuelas de Guadalupe, Salamanca, Toledo, Córdoba, entre otras, y que recogía la influencia de los clásicos como Galeno, Hipócrates, Alejandro de Tralles, Avicena, Arnaldo de Vilanova, Mesué, Bernardino de Laredo, Luis Lobera de Avila, etc. importantes luminarias conocidas por entonces.

- Es muy importante considerar la introducción por España de los más recientes conocimientos del arte médico curativo y práctica asistencial, que debidamente sistematizadas se aplicaron en el Nuevo Mundo, junto con la intervención de notables médicos, cirujanos, barberos, boticarios, flebótomos, ungüentadores, etc, lo que permitió en esta forma organizar las bases de un sistema sanitario debidamente estructurado del Perú, a la vez que controlando el ejercicio profesional por intermedio del Real Protomedicato.

- Es necesario mencionar que precisamente el año de 1551 es el de creación y establecimiento de la Real y Pontificia Universidad de Lima, la primera del Nuevo Continente y por consiguiente decana de todas las que posteriormente se establecieron.

\section{INFORMACIÓN SOBRE LIBROS}

Como se ha mencionado, el inventario y memoria de esta primera Botica contiene abundante y valiosa información sobre los medicamentos y compuestos utilizados en el siglo XVI, y en forma paralela aporta referencias muy específicas sobre las prime- 
ra simientes traídas de España, que fueron sembradas en los grandes campos que rodeaban el Hospital de Santa Ana de los Naturales, y luego propagándose por todo el amplio territorio del Virreinato, como fueron p.e.: laurel, ortigas, borrajas, pino, linaza, coles, nabos, adormideras, peonias, apio, perejil, verdolagas, rábano, mastuerzo, etc.

Además, la información sobre Libros de Medicina y de Farmacia es de gran importancia y significado, por haber constituído el aporte inicial al desarrollo científico y técnico de los sistemas curativos de la salud, y responder a las más recientes y destacadas ediciones de la cultura occidental, como veremos seguidamente:

$1^{\circ}$ «Un Modus Faciendi, encuadernado en tablas, por once reales, 375 maravedís».

Se trata de una obra dedicada a «médicos y boticarios muy común y necesaria. Compilado nuevamente con orden tan peregrina que no se había visto otra vez tan aclarada manera de platicar ni por la orden que ésta lleva», tal como reza el título, cuyo autor es Fray Bernardino de Laredo (1482-1547), médico reconocido en su tiempo, antes de profesar en la Orden de los Mínimos.

La primera edición se hizo en Sevilla en 1527, a cargo del Impresor Jacobo Cromberger, con 228 pgs. más una lámina. La segunda edición se hizo en Sevilla en 1534 y la tercera en 1542 .

El «Modus Faciendi» es considerado el primer libro de Farmacia escrito en castellano, y en su amplio contenido manifiesta la influencia de la tradición farmacéutica árabe en la farmacia española.

Debemos mencionar, que Fray Bernardino expresa que para escribir esta obra contó con la ayuda del doctor Núñez. de Sevilla, del licenciado Rodríguez, en Málaga, y que fue revisada por el doctor Avila, Protomédico del Emperador Carlos I y a su instancia, privilegiado.

$2^{\circ}$ «El Libro del doctor Avila que dicen 'Banquete de los Caballeros', encuadernado en tablas, quince reales, 510 maravedís»

Corresponde a una importante obra de higiene pública, escrita en el año de 1530 por el doctor Luis Lobera de Avila (1480-1551 ) conocido Protomédico del Emperador Carlos I, y cuyo título completo es: «Banquete de nobles caballeros y modo de vivir desde que se levantan hasta que se acuestan, y habla de cada manjar que complexión y propiedad tiene y que daños y provechos hace, y trata del regimiento curativo y preservativo de las fiebres pestilenciales, de la pestilencia y otras cosas utilísimas «. La primera edición se hizo en Ausburg, Alemania, en 1530 por Heinrich Steiner, con 84 hs, y a continuación en 1531 se hizo la traducción alemana. La segunda edición castellana y latina es del año 1542 con el titulo modificado por el autor: «Vergel de Sanidad, que por otro nombre se llamaba 'Banquete de Caballeros' y 
orden de vivir...etc.» corregida y añadida por el indicado, impresa en Alcalá de Henares por Juan de Brocar.

Por la similitud aparente del título con el consignado en la memoria e inventario de la Botica, estimamos que esta segunda edición fué la que llegó a Lima.

$3^{\circ}$ Un Mesué. 13 reales, $442 \mathrm{~ms}$, Existieron dos personajes con el mismo nombre, autores de grandes obras de medicina y farmacia: Juan Mesué, el Viejo y Juan Mesué, el Joven. El primero, fue un médico árabe que ejerció en Bagdad y Damasco en el siglo IX, de gran fama por sus conocimientos y sabios consejos para la curación de enfermedades. Existen pocas ediciones hispánicas de las obras de Juan Mesué, el Viejo, como el «Liber Primus seu methodus medicamenta purgantia....», «Theoria pharmaceutica», «Controversias Pharmacopales», «Tyrocinio Pharmacopeo»,etc.

En cambio, de Juan Mesué, el Joven, se conoce una obra editada entre 1540 y 1541, titulada «Exposición paraphrastica: sobre los cuatro Cánones universales..» En realidad se trata de dos obras góticas muy raras que se guardan en la Biblioteca de la Universidad de Barcelona. Existe información entre los investigadores históricos, más no concordante, que Fray Bernardino de Laredo compiló, copió o tradujo la obra de Mesué. En razón de la diversidad de obras antes citadas, no podemos precisar de éllas cuál fue la que llegó al Perú en 1551.

En cambio, Fray Bernardino de Laredo en su edición del «Modus faciendi» cita en la línea de jarabes las diferentes fórmulas que Mesué había establecido y que venían siendo utilizadas habitualmente en España y en numerosos países europeos (jarabe aceitoso, bizantino, de cidra, ajenjos, cantueso, fumaria, hisopo compuesto, prasio, regaliz, rosas, violetas, yuyubas,etc.).

$4^{\circ}$ Otros libros. Se han encontrado igualmente referencias a otras obras clásicas del siglo XVI, como el «Vocabulario de Antonio» encuadernado en tablas, cuyo valor se consigna en veinte reales, equivalente a 680 maravedís.

\section{PROCESO JUDICIAL Y ARBITRAJE}

El desarrollo del contrato de compañía sobre la Botica, creemos no fue afortunado ni conveniente para el Boticario Francisco de Bilbao; pues a los dos años de vigencia, en el año de 1553 presentó demanda judicial pidiendo resolver el contrato y recuperar las cantidades que estimaba le correspondía, Con fecha 22 de enero de 1555, se otorgó ante el mismo Escribano Real y de Cabildo, Diego Gutiérrez, una escritura cuyo título es por sí solo demostrativo: «Los Hospitales de españoles y de naturales, compromiso con Francisco de Bilbao sobre la compañía de la Botica». 
Por virtud de este compromiso, las partes intervinientes acuerdan poner término al proceso judicial, que les venía causando serios perjuicios, sobre todo a los Hospitales y a la atención de los enfermos. Así deciden someter sus diferencias a un arbitraje de dos personas, del célebre médico y Rector de la Universidad de Lima, doctor Gaspar de Meneses y del Licenciado Francisco de Alva; y para el caso de no llegar a una determinación o por discordia, convienen que las Justicias de la Ciudad nombren un tercer árbitro que con los dos anteriores asista «a ver y determinar lo susodicho», señalándose el término de ocho días para la decisión final, que las partes se obligan a respetar y cumplir, bajo pena de multa de tres mil pesos de oro.

El fundamento de la demanda de Francisco de Bilbao aparece en este instrumento, al expresar que «los hospitales serán más proveídos de las dichas medicinas de que tienen necesidad, teniendo su botica sin pleito. Y porque yo Francisco de Bilbao me quiero ir a los Reinos de España; y porque el fin de los pleitos es dudoso....»

Por el Hospital de Españoles intervienen el Capitán Pedro de Zárate y Martín Yáñez de Estrada, Regidores designados por el Cabildo de la Ciudad. En cambio, por el Hospital de los Naturales actúa el Mayordomo Alvaro de Illescas, con poder especial otorgado por el Arzobispo Fray Jerónimo de Loaisa.

La declaración conjunta de ambas partes es de gran importancia para comprender la magnitud del acuerdo de arbitraje a que decidieron someterse: «Renunciamos, yo el dicho Francisco de Bilbao y los dichos Hospitales, a mi propio fuero y suyo y la ley si conviniere de jurisdictione omnium judicum, para que por todo rigor y más breve remedio de derecho, constriñan, compelen y apremien a mi Francisco de Bilbao y a los dichos Hospitales, así tener, mantener, guardar y cumplir, haciendo en mi persona y bienes y en los bienes propios y rentas de los dichos Hospitales, las ejecuciones, prisiones, ventas y remates de bienes que convengan ser hechas, hasta tanto todo lo que en esta carta contenido haya entero y cumplido efecto, como si todo lo que dicho es fuese dado por sentencia definitiva de juez competente, por no consentida y pasada en cosa juzgada. Y renunciamos todas y cualesquier leyes, fueros, derechos, cartas, mercedes, privilegios, partidas, ordenamientos, auxilios, remedios, declaraciones, definiciones, beneficios y restituciones que en favor de los dichos Hospitales y de mí, Francisco de Bilbao, sean y pueden ser; y en especial renunciamos la ley que dice que general renunciación no vale......»

Se ha logrado determinar por otras fuentes informativas, que Francisco de Bilbao viajó con toda su familia y un nutrido cargamento al Reino de Chile, debiendo pagar la apreciable suma de novecientos pesos de oro por los fletes; estableció botica en la ciudad de Santiago, y el Cabildo de este Ciudad en sesión de 21 de abril de 1566 se ocupó de su persona, con ocasión de las denuncias formuladas por venta de medicamentos a precio elevado.

En cuanto a la Botica, concluído el arreglo y arbitraje con Francisco de Bilbao, permaneció siempre en el Hospital de Santa Ana de los Naturales, donde se había 
instalado desde entonces, por decisión del Arzobispo y del Cabildo de la Hermandad, y designó un Boticario con sueldo mensual encargado de preparar todas las recetas necesarias para los enfermos. Situación que igualmente debió confrontar el Hospital de San Andrés de los Españoles, denominado así desde 1556, en conmemoración de la reunión de la Orden del Toisón de Oro en Barcelona, presidida por el Emperador Carlos I.

FINAL

El Real Hospital de Santa Ana de los Naturales desarrolló su benéfica labor en favor de los indígenas, hombres, mujeres y niños en general, de acuerdo con las Ordenanzas dictadas por el Arzobispo de Los Reyes, Fray Jerónimo de Loaisa; subsistió en su local originario de la Plaza de Santa Ana hasta el año de 1925, en que fue trasladado al nuevo local edificado en la Avenida de Alfonso Ugarte, tomando la denominación de su ilustre y recordado fundador, y donde continúa prestando eficientes servicios a la colectividad, con modernos equipos y profesionales especializados.

El Real Hospital de San Andrés de Españoles y otras castas, con el apoyo del Superior Gobierno, el Cabildo y grandes benefactores, cumplió una efectiva labor de protección y auxilio de los necesitados, fue la sede inicial del Anfiteatro Anatómico establecido en 1792, y hacia 1870 fue trasladado al nuevo y moderno local que con la denominación de «Hospital Dos de Mayo» existe en el Barrio de Cocharcas de Lima, actualmente transformado en moderno centro asistencial general, con eficientes servicios y equipos profesionales distinguidos por su calidad y gran valor humano.

\section{BIBLIOGRAFÍA}

Archivo General de la Nación, Lima, Sección Protocolos Notariales. Libros de Cabildos de la Ciudad de Lima, tomos 1 a 23, Lima 1935-1960.

Biblioteca Nacional del Perú, Secc. Manuscritos, Lima.

Investigación personal del Autor en Archivos y Bibliotecas de Perú y España.

Olmedo Jiménez, M. (1995), Jerónimo de Loaisa, Pacificador de españoles y Protector de Indios, Granada.

Сово, Bernabé (1935), Historia de la Fundación de Lima, Ediciones del IV Centenario, Lima. VARgas Ugarte, Rubén (1951), Historia de la Iglesia en el Perú, Lima, tomos I y II. Lisson Cháves, Emilio (1944), La Iglesia de España en el Perú, Sevilla.

Mendiburu, Manuel DE (1932-1936), Diccionario Histórico Biográfico del Perú, Lima, 2a. Edición.

Sandoval Moraga, Carmen (1985), Reseña histórica de la Farmacia en Chile, Santiago. GÜNCKEL, Hugo (1983), Desarrollo Histórico de la profesión farmacéutica en Chile, Santiago. 